\title{
CO Cleavage and $\mathrm{CO}_{2}$ Functionalization under Mild Conditions by a Multimetallic $\mathrm{CsU}_{2}$ Nitride Complex
}

\author{
Marta Falcone§, Lucile Chatelain, Rosario Scopelliti, and Marinella Mazzanti ${ }^{\star}$
}

§SCS-DSM Award for best poster presentation in Inorganic \& Coordination Chemistry

\begin{abstract}
Novel efficient chemical processes involving cheap and widely accessible carbon dioxide or carbon monoxide under mild conditions for the production of valuable chemical products are highly desirable in the current energetic context. Uranium nitride materials act as high activity catalysts in the Haber-Bosch process but the reactivity of molecular nitride compounds remains unexplored. Here we review recent results obtained in our group showing that a multimetallic nitride complex $\left[\mathrm{Cs}\left\{\left[\mathrm{U}\left(\mathrm{OSi}\left(\mathrm{O}^{t} \mathrm{Bu}\right)_{3}\right)_{3}\right]_{2}(\mu-\mathrm{N})\right\}\right](1)$ with a $\mathrm{CsU}^{\mathbb{I}}-\mathrm{N}-\mathrm{U}^{\mathrm{IV}}$ core, is able to promote $\mathrm{N}-\mathrm{C}$ bond formation due to its strong nucleophile behaviour. In particular, complex $\mathbf{1}$, in the presence of excess $\mathrm{CO}_{2}$ leads to a remarkable dicarbamate product. The multimetallic $\mathrm{CsU}^{\mathrm{IV}}-\mathrm{N}-\mathrm{U}^{\mathrm{IV}}$ nitride also readily cleaves the $\mathrm{C} \equiv \mathrm{O}^{2}$ bond under mild conditions.
\end{abstract}

Keywords: $\mathrm{CO}_{2}$ activation $\cdot \mathrm{CO}$ cleavage $\cdot \mathrm{N}-\mathrm{C}$ bond formation $\cdot$ Nitrides $\cdot$ Uranium

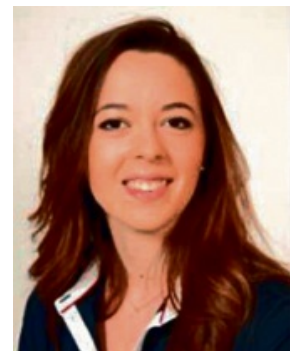

\section{Introduction}

Uranium nitrides are interesting candidates for application in the development of more efficient nuclear fuels, ${ }^{[1]}$ in catalytic $\mathrm{N}$-transfer reactions and small molecule transformation. ${ }^{[2]}$ The reactivity of uranium nitrides remains practically unexplored but the recent characterization of stable mononuclear and dinuclear nitride complexes of uranium in oxidation states ranging from +3 to $+5^{[3]}$ renders accessible the study of the reactivity of these species. Reactions that lead to $\mathrm{N}-\mathrm{C}$ bond formation are of great interest, as they are involved in the synthesis of value-added chemicals such as amino acids or pharmaceutical.[4] It is desirable to design synthetic methods involving the use of cheap and available $\mathrm{C}_{1}$ feedstock such as carbon dioxide. ${ }^{[5]} \mathrm{A}$ handful of examples of transition metals complexes able to form $\mathrm{N}-\mathrm{C}$ bonds from carbon dioxide and activated dinitrogen or nitride complexes ${ }^{[6,7]}$ have been reported but before our reports reviewed here, ${ }^{[8,9]} f$ elements molecular nitrides had not been shown to react with $\mathrm{CO}_{2}$. Another readily available $\mathrm{C}_{1}$ feedstock used in industry for the production of a wide variety of chemicals such as methanol, acetic acid, phosgene and hydrocarbons ${ }^{[10]}$ is carbon monoxide. The cleavage of the carbon oxygen bond, one of the strongest bonds in chemistry (dissociation energy at 298 $\mathrm{K}=1076 \mathrm{~kJ} \mathrm{~mol}^{-1}$ ) is achieved in the Fischer-Tropsch process, used for hydrocarbon production from $\mathrm{CO}$ and $\mathrm{H}_{2}$. This process requires the use of heterogeneous transition-metal catalysts at elevated temperatures. ${ }^{[11]}$ It is an important current challenge to explore new, mild conditions for the $\mathrm{CO}$ cleavage reaction, in the search of new routes for the production of functionalized organic molecules. The direct addition of $\mathrm{CO}$ to a metal-nitride is rare and it is observed only for highly nucleophilic nitride complexes, ${ }^{[3,12]}$ usually leading to the release of the resulting cyanate ligand. ${ }^{[3 n, 12 \mathrm{~d}]}$ Only a few examples of $\mathrm{CO}$ cleavage by metal complexes have been reported so far that led to the formation of metal-carbide complexes and oxo clusters. ${ }^{[13]}$ The binding ${ }^{[14]}$ and the reduction ${ }^{[15]}$ of CO by uranium(III) complexes has been demonstrated. Deltate, ${ }^{[16]}$ squarate ${ }^{[16 b, 17]}$ or ethynediolate dianions ${ }^{[18]}$ have been identified as products in the reaction of uranium(III) compounds with CO. Here, we review the previously reported ${ }^{[8,9]}$ ability of the nitride-bridged diuranium(IV) complex, $\quad\left[\mathrm{Cs}\left\{\left[\mathrm{U}\left(\mathrm{OSi}\left(\mathrm{O}^{\prime} \mathrm{Bu}\right)_{3}\right)_{3}\right] 2(\mu-\mathrm{N})\right\}\right]$ (1), ${ }^{[19]}$ to promote $\mathrm{N}-\mathrm{C}$ bond formation in the reaction with small molecules. The nitride group, bridging two uranium(IV) centers, is highly nucleophilic, and its ability to lead to N-C bond formation allowed us to characterize several new compounds. In particular, in the reactions with $\mathrm{CS}_{2}, \mathrm{CO}_{2}{ }^{[8]}$ and $\mathrm{CO},{ }^{[9]}$ a cyanate/thiocyanate complex, a dicarbamate complex and a cyanide/ oxo complex were formed, respectively. The unusually high nucleophilic character of the nitride leads to complete cleavage of the CO triple bond. We also demonstrated ${ }^{[9]}$ that the direct methylation of the nitride complex 1 leads to Lewis-acid- 
assisted disproportionation of the uranium atom, a completely new reactivity in nitride chemistry.

\section{Reaction with $\mathrm{CO}_{2}$ and $\mathrm{CS}_{2}: \mathrm{N}-\mathrm{C}$ Bond Formation}

We recently showed ${ }^{[8]}$ that complex $\left[\mathrm{Cs}\left\{\left[\mathrm{U}\left(\mathrm{OSi}\left(\mathrm{O}^{t} \mathrm{Bu}\right)_{3}\right)_{3}\right] 2(\mu-\mathrm{N})\right\}\right](\mathbf{1})$, can be stored at $-40^{\circ} \mathrm{C}$, in solution but decomposes at higher temperatures (Scheme 1a). In particular, complex 1 undergoes thermolysis at $80^{\circ} \mathrm{C}$ in toluene to afford the new imidobridged siloxide/silandiolate diuranium(IV) complex, $\left[\mathrm{Cs}\left\{\mathrm{U}_{2}\left(\mathrm{OSi}\left(\mathrm{O}^{t} \mathrm{Bu}\right)_{3}\right)_{5}\left(\mu-\mathrm{N}^{t} \mathrm{Bu}\right)\right.\right.$ $\left.\left.\left(\mu-\mathrm{O}_{2} \mathrm{Si}\left(\mathrm{O}^{t} \mathrm{Bu}\right)_{2}\right)\right\}\right]^{2}(2)$, in $65 \%$ yield. Single crystals suitable for X-ray diffraction were obtained, and the resulting structure of 2 (Fig. 1) clearly showed that a new tert-butylimido bridging group is formed as a consequence of the nucleophilic attack of the nitride on a tert-butyl group of the ligand. Similar reactivity, with elimination of isobutene, has been reported for the diuranium(III) complex $\left[\mathrm{U}\left(\mathrm{OSi}\left(\mathrm{O}^{t} \mathrm{Bu}\right)_{3}\right)_{2}\left(\mu-\mathrm{OSi}\left(\mathrm{O}^{t} \mathrm{Bu}\right)_{3}\right)\right]_{2} \cdot{ }^{[20]}$ The two $\mathrm{U}-\mathrm{N}_{\text {imido }}$ bond lengths found for the tert-butylimide bridge are 2.300(3) and 2.398(3) A, slightly longer than those of dinuclear U(IV) imido complexes (2.156(8)$2.378(3) \AA)$. [21]

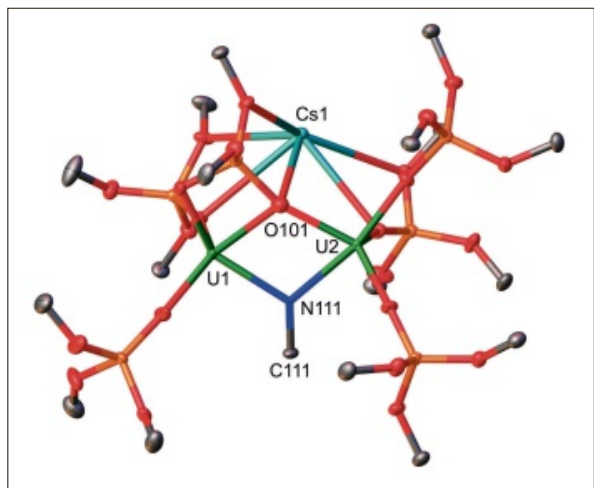

Fig. 1. Thermal ellipsoid drawing of complex 2; probability $50 \%$. Only one carbon atom of the ${ }^{t} \mathrm{Bu}$ groups is shown for clarity. CWiley-VCH Verlag $\mathrm{GmbH} \& \mathrm{Co}$. KGaA. Figure adapted from ref. [8] with permission.

The high nucleophilicity of the bridging nitride inspired us to investigate the reactivity of this complex towards $\mathrm{CS}_{2}$ and $\mathrm{CO}$. We have shown ${ }^{[8]}$ that the reaction of 1 with two equiv. $\mathrm{CS}_{2}$ (Scheme $1 \mathrm{~b}$ ) results in the prompt formation of complex $\left[\mathrm{Cs}\left\{\left[\mathrm{U}\left(\mathrm{OSi}\left(\mathrm{O}^{t} \mathrm{Bu}\right)_{3}\right)_{3}\right]_{2}(\mu-\mathrm{NCS})\left(\mu-\mathrm{CS}_{3}\right)\right\}\right]$ (3) (58\% yield). The crystal structure of $\mathbf{3}$ (Fig. 2) shows the presence of a bridging thiocyanate and a bridging trithiocarbonate ligand, binding the two uranium atoms and the cesium cation in a $\mu_{3}-\kappa^{2}: \kappa^{2}: \kappa^{2}$ fashion. In the $\mathrm{CS}_{3}{ }^{2-}$ unit the charge is clearly delocalised, as indicated by the $\mathrm{C}-\mathrm{S}$ bond lengths (1.740(12), 1.682(9), 1.712(10)

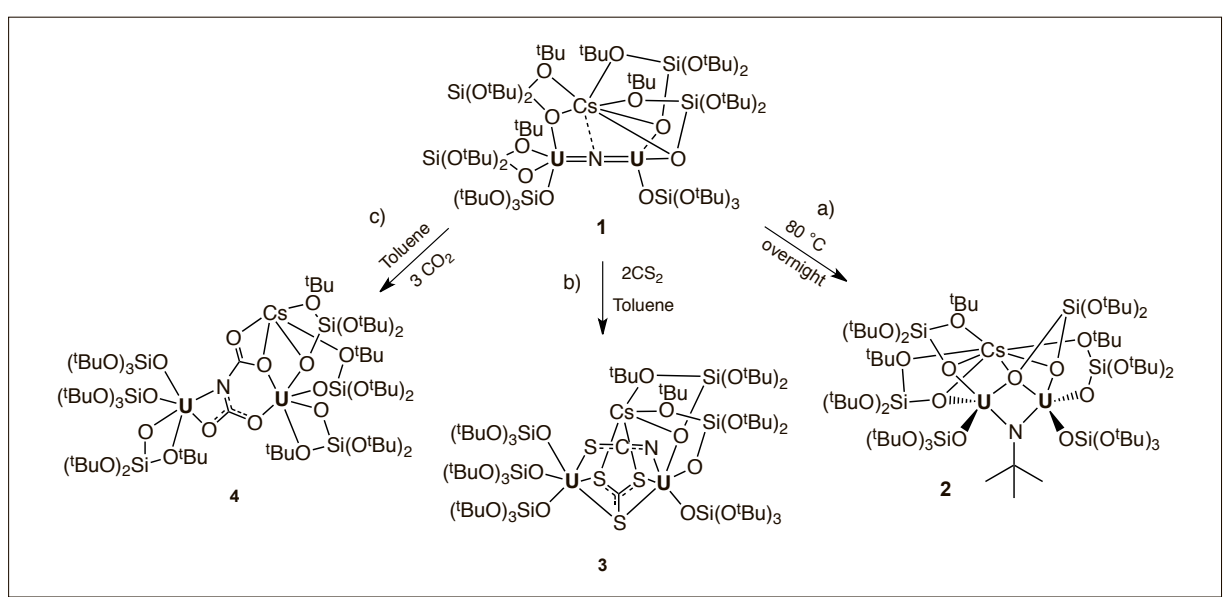

Scheme 1. Reactivity of complex 1: ${ }^{t} \mathrm{Bu}$ transfer from the ligand to the nitrogen atom to form complex 2 (a); reaction with $2 \mathrm{CS}_{2}$ to form complex 3 (b); reaction with $\mathrm{CO}_{2}$ to form complex 4 (c). The products were stored at $-40^{\circ} \mathrm{C}$.

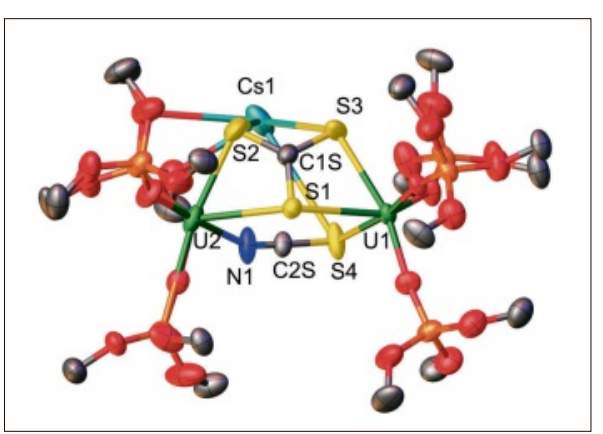

Fig. 2. Thermal ellipsoid drawing of complex 3; probability $50 \%$. Only one carbon atom of the ${ }^{t} \mathrm{Bu}$ groups is shown for clarity. @Wiley- $\mathrm{VCH}$ Verlag $\mathrm{GmbH} \& \mathrm{Co}$. KGaA. Figure adapted from ref. [8] with permission.

$\AA$ A). While two other examples of uranium trithiocarbonate complexes were previously reported, ${ }^{[22]}$ S-bound thiocyanate ligands could not be found in the Cambridge Structural Database.

The presence of the bridging $\mathrm{NCS}^{-}$and $\mathrm{CS}_{3}{ }^{2-}$ ligands was confirmed by ${ }^{13} \mathrm{C} \mathrm{NMR}$ in toluene- $\mathrm{d}_{8}$ (resonances at $124.0 \mathrm{ppm}$ and $195.8 \mathrm{ppm}$ ). The presence of the thiocyanate ligand was also confirmed by IR, which shows two $v\left({ }^{13} \mathrm{CN}\right)$ stretches at 2006 and $2085 \mathrm{~cm}^{-1}$. ${ }^{[23]}$

We have also reported ${ }^{[8]}$ that when only 1 equiv. $\mathrm{CS}_{2}$ is added to $\mathbf{1}$, the ${ }^{13} \mathrm{C} \mathrm{NMR}$ spectrum in $\mathrm{DMSO}-\mathrm{d}_{6}$ shows the presence of free $\mathrm{NCS}^{-}$. This indicates that the formation of complex 3 probably results from the reaction of a sulphide/thiocyanatebridged intermediate, ' $[\mathrm{Cs}\{(\mu-\mathrm{NCS})(\mu-\mathrm{S})$ $\left.\left.\left[\mathrm{U}\left(\mathrm{OSi}\left(\mathrm{O}^{t} \mathrm{Bu}\right)_{3}\right)_{3}\right]_{2}\right\}\right]^{\prime}$, with a second equiv. of $\mathrm{CS}_{2}$. Previous examples of nucleophilic addition of $\mathrm{CS}_{2}$ were shown for a sulphidebridged diuranium(IV) complex ${ }^{[22 \mathrm{a}]}$ and for a $\mathrm{V}(\mathrm{v})$ terminal nitride. ${ }^{[7 \mathrm{~b}]}$

We recently reported ${ }^{[8]}$ that addition of $\mathrm{CO}_{2}$ to complex 1 results in a different reactivity. Complex $\left[\mathrm{Cs}\left\{\left[\mathrm{U}\left(\mathrm{OSi}\left(\mathrm{O}^{t} \mathrm{Bu}\right)_{3}\right)_{3}\right]_{2}(\mu-\right.\right.$ $\left.\mathrm{NC}_{2} \mathrm{O}_{4}\right)$ \}] (4) was formed after addition at low temperature $\left(-70^{\circ} \mathrm{C}\right)$ of 3 equiv. $\mathrm{CO}_{2}$ to 1 (Scheme 1c). The crystal structure of 4 (Fig. 3) shows a dicarbamate ligand, bridging the two uranium atoms forming two fused rings that share one of the new $\mathrm{N}-\mathrm{C}$ bonds. One carbamate oxygen is slightly out of the plane of the dicarbamate ligand and is bound to the cesium cation. In the fragment O122-C121-O121 the negative charge is delocalised (O121-C121 and C121-O122 bond lengths of 1.292(5) and 1.282(4) A) while the double bond character of the C122-O124 bond $(1.229(6) \AA$ ) with respect to C122-O123 (1.317(4) A) suggests charge localisation.

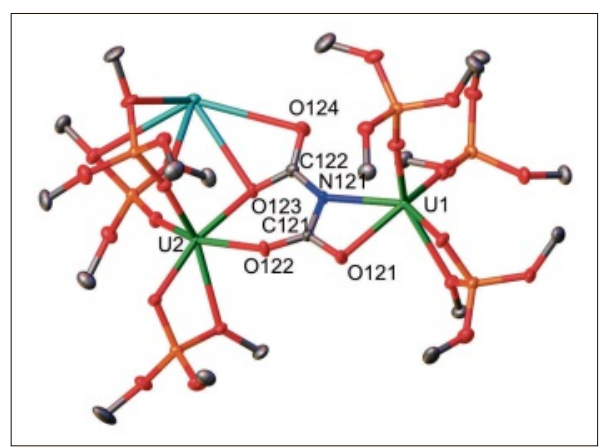

Fig. 3. Thermal ellipsoid drawing of complex 4; probability $50 \%$. Only one carbon atom of the ${ }^{t} \mathrm{Bu}$ groups is shown for clarity. OWiley- $\mathrm{VCH}$ Verlag GmbH \& Co. KGaA. Figure adapted from ref. [8] with permission.

Thus our recent report ${ }^{[8]}$ described the unprecedented insertion of $\mathrm{CO}_{2}$ into a metal nitride, yielding a dicarbamate ligand. Indeed, complexes with the $\mathrm{N}\left(\mathrm{CO}_{2}\right)_{2}{ }^{3-}$ ligand have never been reported, as the synthesis of the protonated species is not trivial.[24] The insertion reactions of $\mathrm{CO}_{2}$ into $\mathrm{U}^{\mathrm{III}}-\mathrm{N}_{\text {amide }}$ or $\mathrm{U}^{\mathrm{IV}}-\mathrm{N}_{\text {amide }}$ bonds resulting in the formation of U(III) or U(IV) O-bound carbamate complexes ${ }^{[25]}$ or U(IV) isocyanate complexes ${ }^{[26]}$ had been reported previously by other groups. However, complex 4 provided the first example of $\mathrm{CO}_{2}$ insertion into a $\mathrm{U}-\mathrm{N}_{\text {nitride }}$ bond. 


\section{Reaction with Carbon Monoxide: C-O Bond Cleavage and N-C Bond Formation.}

We recently showed[9] that the addition of stoichiometric amounts of $\mathrm{CO}$ or ${ }^{13} \mathrm{CO}$ to complex $\left[\mathrm{Cs}\left\{\left[\mathrm{U}\left(\mathrm{OSi}\left(\mathrm{O}^{t} \mathrm{Bu}\right)\right.\right.\right.\right.$ 3)3]2( $\mu-\mathrm{N})\}]$ (1) in toluene at room temperature (Scheme 2a) results in an immediate reaction. The ${ }^{1} \mathrm{H}$ NMR spectrum shows the appearance of a single new signal at $-1.34 \mathrm{ppm}$. Blue crystals of the complex $\quad\left[\mathrm{Cs}\left\{\left[\mathrm{U}\left(\mathrm{OSi}\left(\mathrm{O}^{t} \mathrm{Bu}\right)_{3}\right)_{3}\right]_{2}(\mu-\mathrm{CN})\right.\right.$ $(\mu-\mathrm{O})\}](5)$ were isolated in $60 \%$ yield at $-40{ }^{\circ} \mathrm{C}$ (Fig. 4). The solid-state structure of 5 shows the presence of a diuranium(IV) complex where two uranium atoms are bridged by one oxo ligand and one cyanide ligand. This indicates that the bridging nitride of $\mathbf{1}$ promotes the ready cleavage of carbon monoxide. The resulting cyanide ligand adopts a bridging mode with U-C $(2.609(7) \AA)$ and U-N (2.576(6) $\AA$ ) bond distances comparable to those reported for cyanide bridged diuranium(IV) complexes (2.549(8)-2.583(2) ^). [27]

The reductive carbonylation reactions of $\mathrm{U}(\mathrm{v})$ and $\mathrm{U}(\mathrm{VI})$ mononuclear nitrides were reported to afford $\mathrm{U}^{\mathrm{III}}-\mathrm{OCN}$ and $\mathrm{U}^{\mathrm{IV}}$ OCN complexes respectively. ${ }^{[3 n]}$ The reactivity of complex $\mathbf{1}$ is remarkably different and shows the importance of the multimetallic cooperativity of the two uranium centres and of the $\mathrm{Cs}^{+}$cation to afford complete scission of $\mathrm{CO}$. The importance of such cooperative effect was also evidenced by DFT studies. ${ }^{[9]}$

In order to confirm the presence of a cyanide ligand in complex $\mathbf{5}$ and to investigate the possibility of transferring the cyanide ligand to organic substrates, complex 5 was reacted with $\mathrm{Me}_{3} \mathrm{SiI}$ and with MeOTf (Scheme 2). The ${ }^{13} \mathrm{C}$ NMR spectrum after addition of $\mathrm{Me}_{3} \mathrm{SiI}$ to complex $\mathbf{5}$ showed the appearance of a signal at 126.3 ppm, assigned to the cyanide group of the $\mathrm{Me}_{3} \mathrm{Si}^{13} \mathrm{CN} .{ }^{[12 \mathrm{e}]} \mathrm{The}$ formation of $\mathrm{CH}_{3}{ }^{13} \mathrm{CN}$, after addition of MeOTf to complex $\mathbf{5}$, was also confirmed by ${ }^{13} \mathrm{C}$ NMR, which shows a signal at $113 \mathrm{ppm}$.

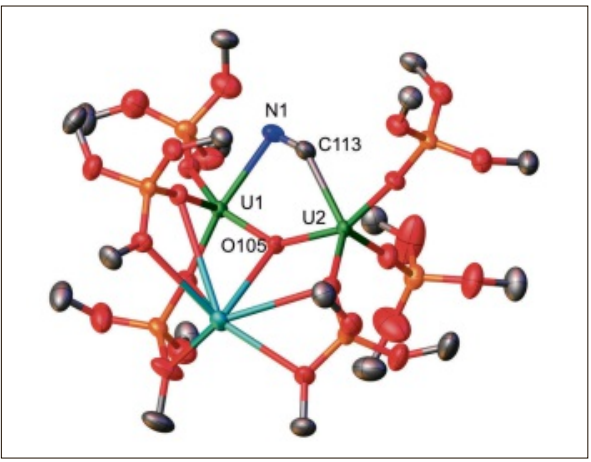

Fig. 4. Molecular structure of complex 5. Thermal ellipsoids depicted at $50 \%$ probability. Only one carbon atom of the ${ }^{t} \mathrm{Bu}$ groups is shown for clarity. Figure adapted from ref. [9].

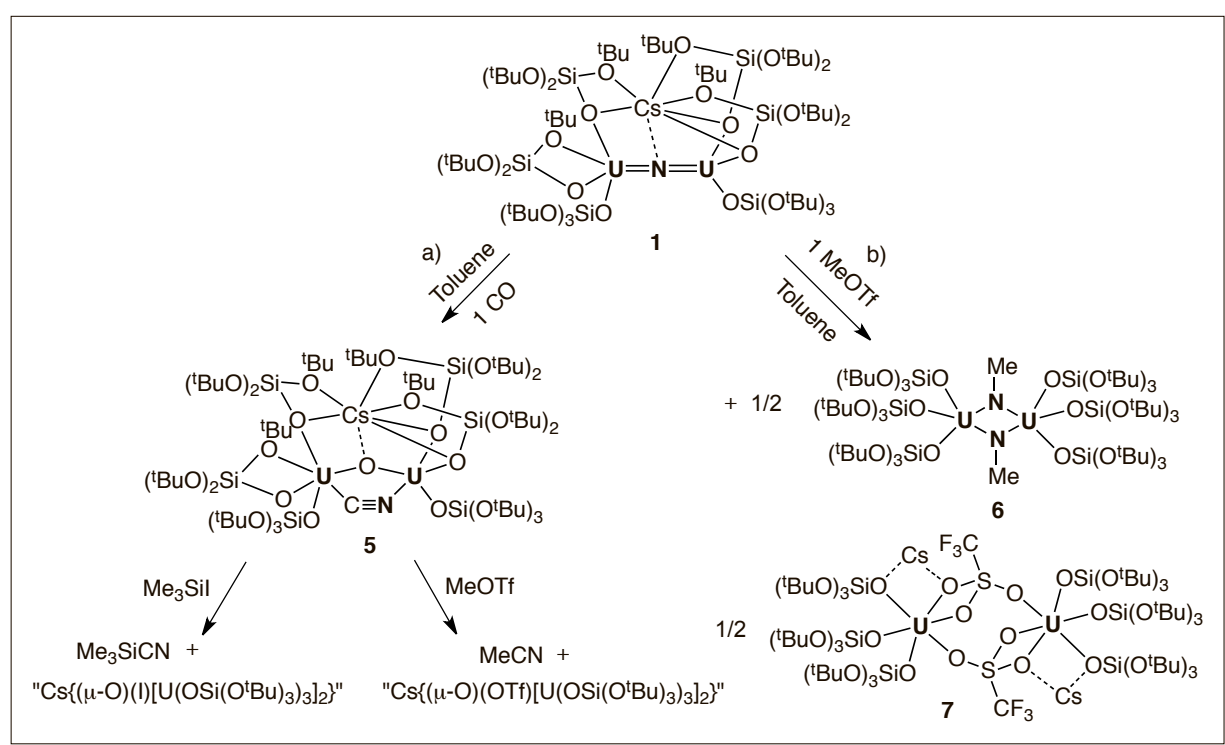

Scheme 2. Reactivity of complex 1: CO cleavage reaction under ambient conditions to afford complex 5 (a) and subsequent addition of the electrophiles MeOTf and $\mathrm{Me}_{3}$ Sil to afford MeCN and $\mathrm{Me}_{3} \mathrm{SiCN}$; methylation reaction with MeOTf to form complexes 6 and 7 (b).

We also showed ${ }^{[9]}$ that the reaction of 1 with one equivalent of MeOTf at room temperature results in a slow reaction affording a mixture of complexes $\left[\left\{\mathrm{U}^{\mathrm{V}}\left(\mathrm{OSi}\left(\mathrm{O}^{t} \mathrm{Bu}\right)_{3}\right)_{3}\right\}_{2}(\mu-\mathrm{NMe})_{2}\right] \quad(\mathbf{6})$ and $\mathrm{Cs}_{2}\left[\left\{\mathrm{U}\left(\mathrm{OSi}\left(\mathrm{O}^{t} \mathrm{Bu}\right)_{3}\right)_{3}\right\}_{2}(\mu-\mathrm{OTf})_{2}\right] \cdot 2\left(\mathrm{C}_{7} \mathrm{H}_{8}\right)$ (7) (Scheme 2b). The solution was kept at $-40{ }^{\circ} \mathrm{C}$ and light blue crystals of the bis(imido) complex 6 were recovered after $24 \mathrm{~h}$. Attempts to isolate the two products in a pure form from this reaction were not successful. However, the reaction of complex 1 with 2 equiv. MeOTf resulted in the isolation of complex 7 in $60 \%$ yield.

The crystal structure of $\mathbf{6}$ (Fig. 5a) shows two independent diuranium(v) complexes (only one is shown in Fig. 5a) where two uranium atoms are bridged by two methylimido ligands. The solid-state structure of 7 (Fig. 5b) shows a diuranium(III) complex where two uranium atoms are bridged by two triflate anions, each one binding the two uranium centres and a cesium cation.

Thus, the alkylation of $\mathbf{1}$ promotes the valence disproportionation of U(IV) into $\mathrm{U}(\mathrm{v})$ and $\mathrm{U}(\mathrm{III})$. This exceptional reactivity is remarkable since $\mathrm{U}(\mathrm{III})$ and $\mathrm{U}(\mathrm{v})$ complexes are usually more prone to disproportionation, ${ }^{[28]}$ while U(IV) complexes are generally much more stable.

\section{Conclusion}

In conclusion our recent work ${ }^{[8,9]}$ demonstrated that nitride functionalization with heteroallenes is readily effected by uranium. The work opens up new selective pathways for the synthesis of new organic molecules from cheap $\mathrm{CO}_{2}$ feedstock and metal nitrides. Moreover, the high nucleophilic reactivity of the nitride ligand in the
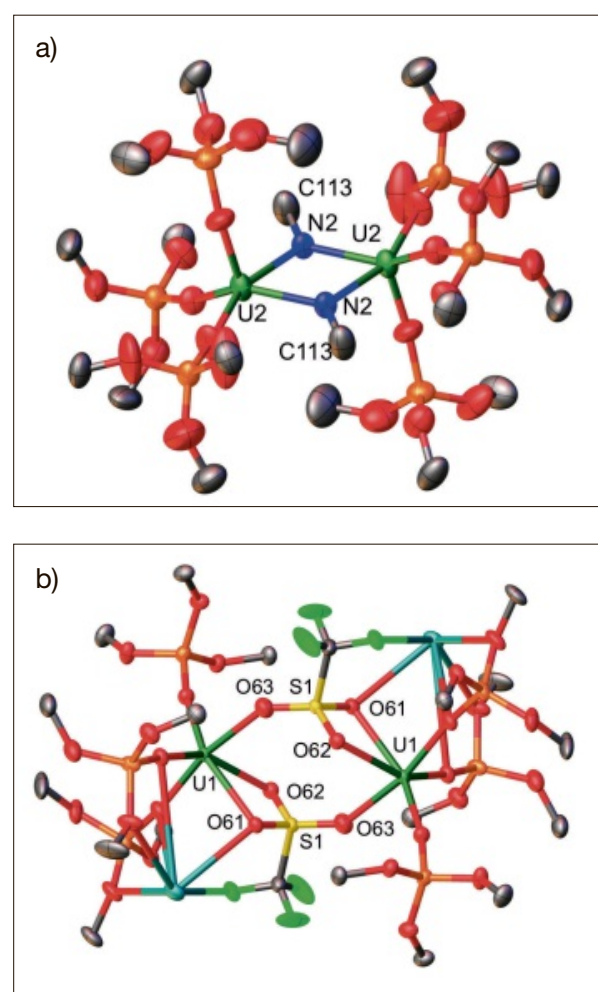

Fig. 5. Thermal ellipsoid drawing of complex 6 (only one complex is displayed) (a) and for $\mathrm{Cs}_{2}\left[\left\{\mathrm{U}\left(\mathrm{OSi}\left(\mathrm{O}^{t} \mathrm{Bu}\right)_{3}\right)_{3}\right\}_{2}(\mu-\mathrm{OTf})_{2}\right] \cdot 2\left(\mathrm{C}_{7} \mathrm{H}_{8}\right) 7$ (b); probability $50 \%$. Only one carbon atom of the ${ }^{t} \mathrm{Bu}$ groups is shown for clarity. Figure adapted from ref [9].

heterodimetallic $\mathrm{CsU}=\mathrm{N}=\mathrm{U}$ nitride led to the first example of complete cleavage of $\mathrm{CO}$ by a nitride complex under ambient conditions. The $\mathrm{CO}$ cleavage affords a new complex containing two U(IV) cations bridged by an oxo and a cyanide group. This complex can transfer the cyanide group to electrophiles leading to $\mathrm{N}-\mathrm{C}$ bond 
formation and release of organic molecules such as $\mathrm{CH}_{3} \mathrm{CN}$ or $\mathrm{CH}_{3} \mathrm{SiCN}$.

The potential of these multimetallic uranium nitrides is highlighted by the fact that bridging nitrides of transition metals are often inert. The work demonstrated the possibility of implementing the selective synthesis of organic molecules from abundant and cheap $\mathrm{CO}$ and $\mathrm{CO}_{2}$ feedstocks using metal nitrides. Such novel reactivity of uranium nitrides will certainly promote the development of new methods that involve both stoichiometric and catalytic N-C bond formation.

\section{Acknowledgements}

We acknowledge support from the Swiss National Science Foundation and from the Ecole Polytechnique Fédérale de Lausanne (EPFL).

Received: February 10, 2017

[1] a) A. R. Fox, S. C. Bart, K. Meyer, C. C. Cummins, Nature 2008, 455, 341; b) M. J. Monreal, P. L. Diaconescu, Nat. Chem. 2010, 2, 423; c) G. W. C. Silva, C. B. Yeamans, A. P. Sattelberger, T. Hartmann, G. S. Cerefice, K. R. Czerwinski, Inorg. Chem. 2009, 48, 10635.

[2] a) F. Haber, Vol. DE 229126, Haber, F Ammonia German patent DE 229126, 1909; b) A. R. Fox, S. C. Bart, K. Meyer, C. C. Cummins, Nature 2008, 455, 341; c) M. S. Eisen, Top. Organomet. Chem. 2010, 31, 157.

[3] a) D. M. King, S. T. Liddle, Coord. Chem. Rev. 2014, 266, 2; b) T. W. Hayton, Chem. Commun. 2013, 49, 2956; c) W. J. Evans, S. A. Kozimor, J. W. Ziller, Science 2005, 309, 1835; d) I. Korobkov, S. Gambarotta, G. P. A. Yap, Angew. Chem. Int. Ed. 2002, 41, 3433; e) T. K. Todorova, L. Gagliardi, J. R. Walensky, K. A. Miller, W. J. Evans, J. Am. Chem. Soc. 2010, 132, 12397; f) G. Nocton, J. Pecaut, M. Mazzanti, Angew. Chem. Int. Ed. 2008, 47, $3040 ;$ g) S. Fortier, G. Wu, T. W. Hayton, J. Am. Chem. Soc. 2010, 132, 6888; h) A. R. Fox, P. L. Arnold, C. C. Cummins, J. Am. Chem. Soc. 2010, 132, 3250; i) C. Camp, J. Pecaut, M. Mazzanti, J. Am. Chem. Soc. 2013, 135, 12101; j) L. Maria, I. C. Santos, V. R. Sousa, J. Marcalo, Inorg. Chem. 2015, 54, 9115; k) R. K. Thomson, T. Cantat, B. L. Scott, D. E. Morris, E. R. Batista, J. L. Kiplinger, Nat. Chem. 2010, 2, 723; 1) D. M. King, F. Tuna, E. J. L. McInnes, J. McMaster, W. Lewis, A. J. Blake, S. T. Liddle, Nat. Chem. 2013, 15, 482; m) D. M. King, F. Tuna, E. J. L. McInnes, J. McMaster, W. Lewis, A. J. Blake, S. T. Liddle, Science 2012, 337, 717; n) P. A. Cleaves, D. M. King, C. E. Kefalidis, L. Maron, F. Tuna, E. J. L. McInnes, J. McMaster, W. Lewis, A. J. Blake, S. T. Liddle, Angew. Chem. Int. Ed. 2014, 53, 10412; o) L. Chatelain, R. Scopelliti, M. Mazzanti, J. Am. Chem. Soc. 2016, 138,
1784; p) N. Tsoureas, A. F. R. Kilpatrick, C. J. Inman, F. G. N. Cloke, Chem. Sci. 2016, 7, 4624.

[4] S. D. Roughley, A. M. Jordan, J. Med. Chem. 2011, 54, 3451 .

[5] M. Aresta, A. Dibenedetto, J. Chem. Soc.Dalton Trans. 2007, 2975.

[6] a) W. H. Bernskoetter, E. Lobkovsky, P. J. Chirik, Angew. Chem. Int. Ed. 2007, 46, 2858; b) D. J. Knobloch, H. E. Toomey, P. J. Chirik, J. Am. Chem. Soc. 2008, 130, 4248.

[7] a) J. M. Smith, Prog. Inorg. Chem. 2014, 58, 417; b) J. K. Brask, V. Dura-Vila, P. L. Diaconescu, C. C. Cummins, Chem. Commun. 2002, 902; c) J. S. Silvia, C. C. Cummins, $J$. Am. Chem. Soc. 2010, 132, 2169.

[8] M. Falcone, L. Chatelain, M. Mazzanti, Angew. Chem. Int. Ed. 2016, 55, 4074

[9] M. Falcone, C. E. Kefalidis, R. Scopelliti, L. Maron, M. Mazzanti, Angew. Chem. Int. Ed. 2016, $55,12290[10] \quad$ G. W. Parshall, S. D. Ittel, 'Homogeneous Catalysis. The Applications and Chemistry of Catalysis by Soluble Transition Metal Complexes', 2nd ed., Wiley Interscience, 1992.

[11] H. Schulz, Appl. Catal. A 1999, 186, 3.

[12] a) B. Askevold, J. T. Nieto, S. Tussupbayev, M. Diefenbach, E. Herdtweck, M. C. Holthausen, S. Schneider, Nat. Chem. 2011, 3, 532; b) J. J. Scepaniak, R. P. Bontchev, D. L. Johnson, J. M. Smith, Angew. Chem. Int. Ed. 2011, 50, 6630; c) B. L. Tran, M. Singhal, H. Park, O. P. Lam, M. Pink, J. Krzystek, A. Ozarowski, J. Telser, K. Meyer, D. J. Mindiola, Angew. Chem. Int. Ed. 2010, 49, 9871; d) J. S. Silvia, C. C. Cummins, J. Am. Chem. Soc. 2009, 131, 446; e) S. P. Semproni, C. Milsmann, P. J. Chirik, Angew. Chem. Int. Ed. 2012, 51, 5213.

[13] a) F. Calderazzo, U. Englert, A. Guarini, F. Marchetti, G. Pampaloni, A. Segre, Angew. Chem. Int. Ed. 1994, 33, 1188; b) N. M. West, A. J. M. Miller, J. A. Labinger, J. E. Bercaw, Coord. Chem. Rev. 2011, 255, 881; c) D. R. Neithamer, R. E. Lapointe, R. A. Wheeler, D. S. Richeson, G. D. Vanduyne, P. T. Wolczanski, J. Am. Chem. Soc. 1989, 111, 9056; d) R. L Miller, P. T. Wolczanski, A. L. Rheingold, $J$. Am. Chem. Soc. 1993, 115, 10422; e) T. Shima, Z. Hou, J. Am. Chem. Soc. 2006, 128, 8124; f) J. Ballmann, F. Pick, L. Castro, M. D. Fryzuk, L. Maron, Organometallics 2012, 31, 8516; g) A. S. Batsanov, J. A. Cabeza, M. G. Crestani, M. R. Fructos, P. Garcia-Alvarez, M. Gille, Z. Lin, T. B. Marder, Angew. Chem. Int. Ed. 2016 , 55,4707 ; h) P. A. Belmonte, F. G. N. Cloke, R. R. Schrock, J. Am. Chem. Soc. 1983, 105, 2643; i) J. A. Buss, T. Agapie, Nature 2016, 529, 72; j) D. J. Knobloch, E. Lobkovsky, P. J. Chirik, J. Am. Chem. Soc. 2010, 132, 10553; k) T. Matsuo, H. Kawaguchi, J. Am. Chem. Soc. 2005, 127, 17198; 1) H. Braunschweig, M. A. Celik, R. D. Dewhurst, S. Kachel, B. Wennemann, Angew. Chem. Int. Ed. 2016, 55, 5076.

[14] a) J. G. Brennan, R. A. Andersen, J. L. Robbins, J. Am. Chem. Soc. 1986, 108, 335; b) J. Parry, E. Carmona, S. Coles, M. Hursthouse, J. Am. Chem. Soc. 1995, 117, 2649; c) W. J. Evans, S. A. Kozimor, G. W. Nyce, J. W. Ziller, J. Am. Chem. Soc. 2003, 125, 13831 .

[15] I. Castro-Rodriguez, K. Meyer, J. Am. Chem. Soc. 2005, 127, 11242.
[16] a) O. T. Summerscales, F. G. N. Cloke, P. B. Hitchcock, J. C. Green, N. Hazari, Science 2006, 311, 829; b) A. S. Frey, F. G. N. Cloke, P. B. Hitchcock, I. J. Day, J. C. Green, G. Aitken, J. Am. Chem. Soc. 2008, 130, 13816.

[17] O. T. Summerscales, F. G. N. Cloke, P. B. Hitchcock, J. C. Green, N. Hazari, J. Am. Chem. Soc. 2006, 128, 9602

[18] a) P. L. Arnold, Z. R. Turner, R. M. Bellabarba, R. P. Tooze, Chem. Sci. 2011, 2, 77; b) S. M. Mansell, N. Kaltsoyannis, P. L. Arnold, J. Am. Chem. Soc. 2011, 133, 9036; c) B. M. Gardner, J. C. Stewart, A. L. Davis, J. McMaster, W. Lewis, A. J. Blake, S. T. Liddle, Proc. Natl. Acad. Sci. USA 2012, 109, 9265.

[19] C. Camp, J. Pecaut, M. Mazzanti, J. Am. Chem. Soc. 2013, 135, 12101.

[20] C. Camp, C. E. Kefalidis, J. Pecaut, L. Maron, M. Mazzanti, Angew. Chem. Int. Ed. 2013, 52, 12646.

[21] a) J. G. Brennan, R. A. Andersen, A. Zalkin, J. Am. Chem. Soc. 1988, 110, 4554; b) J. L. Stewart, R. A. Andersen, New J. Chem. 1995 19,587 ; c) R. C. Schnabel, B. L. Scott, W. H. Smith, C. J. Burns, J. Organomet. Chem. 1999, $591,14$.

[22] a) O. P. Lam, L. Castro, B. Kosog, F. W Heinemann, L. Maron, K. Meyer, Inorg. Chem. 2012, 51, 781; b) C. Camp, O. Cooper, J. Andrez, J. Pecaut, M. Mazzanti, J. Chem. Soc.Dalton Trans. 2015, 44, 2650

[23] M. A. S. Goher, Coll. Czech. Chem. Commun. 1977, 42, 1478

[24] R. B. MacMullin, US. Pat. 43178, 1935.

[25] P. J. Fagan, J. M. Manriquez, S. H. Vollmer, C. S. Day, V. W. Day, T. J. Marks, J. Am. Chem. Soc. 1981, 103, 2206.

[26] C. Camp, L. Chatelain, C. E. Kefalidis, J. Pécaut, L. Maron, M. Mazzanti, Chem. Commun. 2015, $51,15454$.

[27] a) J.-C. Berthet, P. Thuery, M. Ephritikhine, J. Chem. Soc.-Dalton Trans. 2015, 44, 7727; b) A Herve, Y. Bouzidi, J.-C. Berthet, L. Belkhiri, P. Thuery, A. Boucekkine, M. Ephritikhine, Inorg. Chem. 2014, 53, 6995.

[28] 'The Chemistry of the Actinide and Transactinide Elements', Eds. L. R. Morss, N. Edelstein, J. Fuger, J. J. Katz, 3rd ed., Springer, Dordrecht, 2006. 